\title{
Longitudinal studies confirm faster telomere erosion in short-lived bird species
}

\author{
Joanna Sudyka $^{1} \cdot$ Aneta Arct $^{1} \cdot$ Szymon Drobniak $^{1} \cdot$ Lars Gustafsson $^{2} \cdot$ \\ Mariusz Cichoń ${ }^{1}$
}

Received: 11 May 2015/Revised: 14 October 2015/Accepted: 5 November 2015/Published online: 8 December 2015

(C) The Author(s) 2015. This article is published with open access at Springerlink.com

\begin{abstract}
Evidence is accumulating that telomeres become shorter with advancing age and possibly explain some of the observed variation in longevity. Cross-sectional analyses have shown that species with shorter lifespans lose more telomeric repeats with age than species with longer lifespans. Using existing data from longitudinal studies performed on several bird species, we confirmed a negative relationship between the rate of telomere shortening and maximum longevity.
\end{abstract}

Keywords Ageing · Wild population · Blue Tit . Longevity $\cdot$ Lifespan

\section{Zusammenfassung}

\section{Längsschnittuntersuchungen bestätigen schnellere Telomer-Verkürzung bei kurzlebigen Vogelarten}

Es gibt immer mehr Belege dafür, dass die Telomere mit wachsendem Lebensalter immer kürzer werden und damit möglicherweise bestimmte Variationen in der Lebensdauer erklärt werden können. Querschnittsanalysen haben

Communicated by M. Wink.

Electronic supplementary material The online version of this article (doi:10.1007/s10336-015-1304-4) contains supplementary material, which is available to authorized users.

Joanna Sudyka

joanna.sudyka@uj.edu.pl

1 Institute of Environmental Sciences, Jagiellonian University, ul. Gronostajowa 7, 30-387 Kraków, Poland

2 Department of Animal Ecology/Ecology and Genetics, Uppsala University, Norbyvägen 18D, 75236 Uppsala, Sweden gezeigt, dass kurzlebige Arten mit wachsendem Alter mehr der vielen Wiederholungs-Sequenzen am Ende ihrer Telomere verlieren als Arten mit längerer Lebensdauer. Aufgrund vorhandener Daten aus Längsschnittsstudien an einigen Vogelarten können wir eine negative Korrelation zwischen Telomer-Verkürzung und maximaler Lebensspanne bestätigen.

\section{Introduction}

Telomeres are repeats of non-coding DNA located at the ends of chromosomes. They protect chromosomes from losing essential DNA, as the replication process is never complete on the lagging strand. Because of this so-called end-replication problem telomeres become shorter with each cell division. Analysing telomere length may provide a suitable tool to assess biological ageing as it is perceived to be a reliable ageing biomarker (Monaghan and Haussmann 2006). It has been shown that telomere length at young age predicts longevity (Heidinger et al. 2012) and the telomere length itself as well as the rate of telomere erosion can constitute a better estimator of life expectancy than chronological age (Bize et al. 2009). Nevertheless, telomere dynamics is still poorly understood. Telomeres do not shrink at a constant rate and the variation observed in telomere length among individuals of the same age is substantial (Monaghan and Haussmann 2006). In this context it is important to trace within-individual changes in telomere length. Therefore increasing numbers of studies apply a within-individual, longitudinal approach while exploring telomere dynamics. However, longitudinal studies are difficult, particularly in the wild, as a result of the great effort required for multiple sampling of the same 
individuals. The majority of studies were performed on long-lived birds while telomere length was measured only twice in the entire lifespan of an individual (Hall et al. 2004; Pauliny et al. 2006; Bize et al. 2009; Bauch et al. 2013; Young et al. 2013), but see Salomons et al. (2009), Barrett et al. (2013) and Asghar et al. (2015). To our knowledge short-lived species have been considered in longitudinal studies of telomere dynamics only recently (Heidinger et al. 2012; Asghar et al. 2015); therefore a between-species comparative study of lifespan-dependent telomere erosion on an intra-individual level was not possible until now. The existing cross-sectional analyses indicate that short-lived animals face more rapid telomere decay than long-lived ones (Haussmann et al. 2003). However, in cross-sectional comparisons the interpretation of telomere dynamics in older age classes is difficult, as disappearance of individuals from a population may not be independent from telomere length. This may be particularly important if age-related telomere shortening shows significant individual variation.

Here we used existing data on telomere dynamics from longitudinal studies to test the hypothesis that the rate of telomere loss is related to maximum observed longevity. Since most studies have been performed on long-lived species, we also included another short-lived passerine, the Blue Tit (Cyanistes caeruleus) from our own unpublished work.

\section{Methods}

We performed correlation analysis to test if the rate of telomere loss is related to maximum observed longevity using published data. We considered all studies on adult birds that used a longitudinal approach and gave information on telomere loss across age classes (see electronic supplementary material for details). From the analysis we excluded studies in which birds had undergone any experimental manipulation that may alter natural telomere dynamics (this led to the exclusion of eight out of 18 papers on bird longitudinal telomere dynamics that we are aware of). In these papers the data on telomeres were given in various forms. Some provide direct information on telomere length/telomere loss whereas in others telomere loss could only be estimated from figures. Since telomere length is often expressed in relative values (qPCR results) it was not possible to calculate telomere loss in absolute values. Telomere loss in base pairs was only given in five papers, all for long-lived species. Additionally, absolute change in telomere length is less informative as species differ in telomere length. To solve this issue, telomere erosion was assessed as yearly telomere loss approximated as the difference between mean telomere length in the first and last age class reported in the paper divided by the number of years between sampling. This value was expressed as a percentage of average telomere length calculated across reported age classes.

We also included our own unpublished data from a wild population of Blue Tit inhabiting Gotland, an island in the Baltic Sea. We assessed within-individual telomere shortening in 30 samples originating from 10 birds using qPCR techniques (see Sudyka et al. 2014 for details on the population and telomere measurement). Here we selected individuals that were sampled at the early stage of life and monitored for at least 3 years to make the rate of telomere loss representative for the whole lifespan. On average these birds were sampled three times across their lifetime while maximum longevity observed in our population is 7 years. Analyses were performed in SPSS v.22.

\section{Results and discussion}

Cross-sectional analyses have shown that short-lived species experience faster shortening of telomeres than longlived species (Haussmann et al. 2003). Here we confirmed this finding using a within-individual approach. Yearly telomere shortening in Blue Tits observed in our data $(12.4 \%)$ is one of the highest rates reported for birds. A similarly high rate of telomere shortening was reported in Zebra Finches (Heidinger et al. 2012) and Great Reed Warblers (Asghar et al. 2015), showing comparable longevity to the Blue Tit. In long-lived species yearly telomere length change varies from +1.5 to $-5.5 \%$ (electronic supplementary material and Fig. 1). Our analysis of published longitudinal data on telomere dynamics confirmed the negative relationship between the rate of telomere shortening and maximum longevity (Fig. 1, $r=0.839$, $N=10, P=0.002$ ), as previously detected by Haussmann et al. (2003) using cross-sectional data. One of the species (the Thick-billed Murres) experienced yearly telomere lengthening. This may stem from the fact that the exact age of studied individuals was not known and telomere change had been studied only between two subsequent years. Therefore we ran an analysis excluding this study to reconfirm the observed relationship between yearly changes in telomere length and longevity. After excluding the Thick-billed Murres the correlation still holds true $(r=0.834, P=0.005)$. In fact, some other studies on long-lived species could not detect telomere shortening either (e.g. Haussmann et al. 2003). Possibly long-lived birds possess more efficient mechanisms protecting against replicative senescence such as higher telomerase activity throughout life (Haussmann et al. 2007). Another explanation involves different rates of red blood cell turnover in those species directly related to metabolic rate. Yet the link 


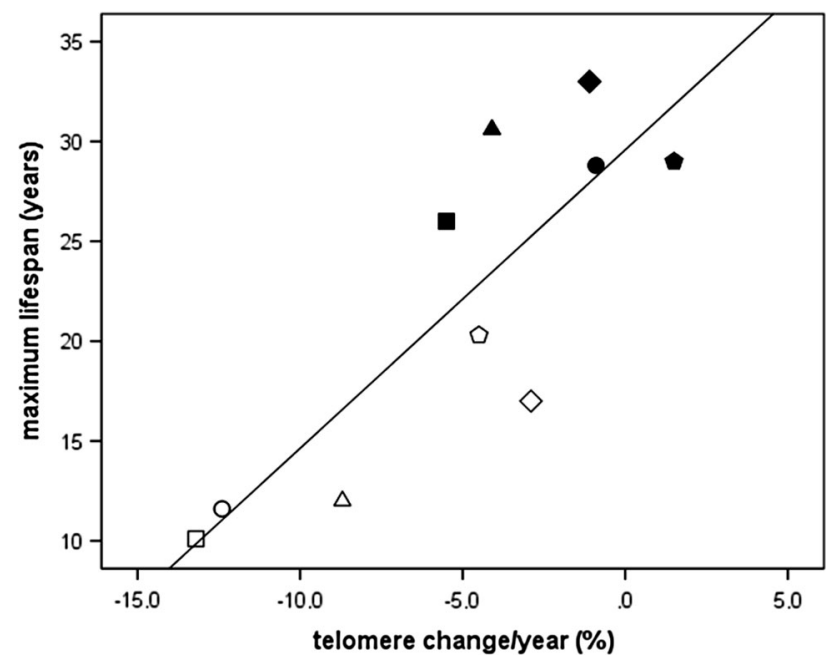

Fig. 1 Relationship between mean telomere change rate expressed in $\%$ of mean telomere length across age classes and maximum observed lifespan from published longitudinal studies on birds. The line (maximum observed lifespan $=29.58+1.49 \%$ telomere change) is the best-fit regression through the data $\left(F_{1,8}=19.022, P=0.002\right.$, $\left.R^{2}=0.70\right)$. Thick-billed Murre black pentagon, Dunlin black circle, Common Tern black diamond, Seychelles Warbler open diamond, European Shag black triangle, Jackdaw open pentagon, Alpine Swift black square, Zebra Finch open triangle, Blue Tit open circle, Great Reed Warbler open square

between metabolic rate and longevity in birds and mammals remains ambiguous (Buttemer et al. 2010; Hulbert 2010). Slower metabolism should generate less reactive oxygen species (ROS) which are particularly harmful to telomeres (Monaghan and Haussmann 2006) and in general ROS levels are inversely related to maximum lifespan (Buttemer et al. 2010). Such a relationship was reported in mammals (Ku et al. 1993), but not confirmed among birds (Montgomery et al. 2012b). Long-lived birds, however, appear to be more resistant to damage by ROS owing to more efficient antioxidative protection (Montgomery et al. 2012a).

Acknowledgments This research was financed by the grant of the Polish National Science Center no. DEC-2013/09/N/NZ8/03211 and the preliminary studies by the Jagiellonian University DS/MND/ WBiNoZ/INoŚ/24/2012, both awarded to JS. This publication was also supported by funding from the Jagiellonian University within the SET project (to AA and SD). We are thankful to Anna Dubiec, Edyta Podmokła and Dariusz Wiejaczka for their assistance in the fieldwork.

Open Access This article is distributed under the terms of the Creative Commons Attribution 4.0 International License (http://crea tivecommons.org/licenses/by/4.0/), which permits unrestricted use, distribution, and reproduction in any medium, provided you give appropriate credit to the original author(s) and the source, provide a link to the Creative Commons license, and indicate if changes were made.

\section{References}

Asghar M, Hasselquist D, Zehtindjiev P et al (2015) Hidden costs of infection: chronic malaria accelerates telomere degradation and senescence in wild birds. Science 347:436-438

Barrett ELB, Burke TA, Hammers M et al (2013) Telomere length and dynamics predict mortality in a wild longitudinal study. Mol Ecol 22:249-259. doi:10.1111/mec.12110

Bauch C, Becker PH, Verhulst S (2013) Telomere length reflects phenotypic quality and costs of reproduction in a long-lived seabird. Proc Biol Sci 280:20122540. doi:10.1098/rspb.2012. 2540

Bize P, Criscuolo F, Metcalfe NB et al (2009) Telomere dynamics rather than age predict life expectancy in the wild. Proc Biol Sci 276:1679-1683. doi:10.1098/rspb.2008.1817

Buttemer WA, Abele D, Costantini D (2010) From bivalves to birds: oxidative stress and longevity. Funct Ecol 24:971-983. doi:10. 1111/j.1365-2435.2010.01740.x

Hall ME, Nasir L, Daunt F et al (2004) Telomere loss in relation to age and early environment in long-lived birds. Proc Biol Sci 271:1571-1576. doi:10.1098/rspb.2004.2768

Haussmann MF, Winkler DW, O'Reilly KM et al (2003) Telomeres shorten more slowly in long-lived birds and mammals than in short-lived ones. Proc Biol Sci 270:1387-1392. doi:10.1098/ rspb.2003.2385

Haussmann MF, Winkler DW, Huntington CE et al (2007) Telomerase activity is maintained throughout the lifespan of long-lived birds. Exp Gerontol 42:610-618. doi:10.1016/j.exger.2007.03. 004

Heidinger BJ, Blount JD, Boner W et al (2012) Telomere length in early life predicts lifespan. Proc Natl Acad Sci USA 109:1743-1748. doi:10.1073/pnas.1113306109

Hulbert AJ (2010) Metabolism and longevity: is there a role for membrane fatty acids? Integr Comp Biol 50:808-817. doi:10. 1093/icb/icq007

Ku H, Brunk U, Sohal R (1993) Relationship between mitochondrial superoxide and hydrogen peroxide production and longevity of mammalian species. Free Radic Biol Med 15:621-627

Monaghan P, Haussmann MF (2006) Do telomere dynamics link lifestyle and lifespan? Trends Ecol Evol 21:47-53. doi:10.1016/ j.tree.2005.11.007

Montgomery MK, Hulbert AJ, Buttemer WA (2012a) Does the oxidative stress theory of aging explain longevity differences in birds? I. Mitochondrial ROS production. Exp Gerontol 47:203-210. doi:10.1016/j.exger.2011.11.006

Montgomery MK, Buttemer WA, Hulbert AJ (2012b) Does the oxidative stress theory of aging explain longevity differences in birds? II. Antioxidant systems and oxidative damage. Exp Gerontol 47:211-222. doi:10.1016/j.exger.2011.11.014

Pauliny A, Wagner RH, Augustin J et al (2006) Age-independent telomere length predicts fitness in two bird species. Mol Ecol 15:1681-1687. doi:10.1111/j.1365-294X.2006.02862.x

Salomons HM, Mulder GA, van de Zande L et al (2009) Telomere shortening and survival in free-living corvids. Proc Biol Sci 276:3157-3165. doi:10.1098/rspb.2009.0517

Sudyka J, Arct A, Drobniak S et al (2014) Experimentally increased reproductive effort alters telomere length in the blue tit (Cyanistes caeruleus). J Evol Biol 27:2258-2264. doi:10.1111/ jeb. 12479

Young RC, Kitaysky AS, Haussmann MF et al (2013) Age, sex, and telomere dynamics in a long-lived seabird with male-biased parental care. PLoS One 8:1-8. doi:10.1371/journal.pone. 0074931 